\title{
PENGARUH AUTOGENIC DAN HANDGRIP RELAXATION TERHADAP ASPEK FISIKDAN ASPEK PSIKOLOGIS, PADA PENDERITA KANKER PAYUDARA YANG MENJALANI KEMOTERAPI
}

\author{
Mareta Dea Rosaline $^{1}$, Desak Agung Suprabawati ${ }^{2}$, Hanik Endang Nihayati ${ }^{3}$ \\ Magister Keperawatan, Fakultas Keperawatan, Universitas Airlangga \\ Email: Maretadea9@gmail.com
}

\begin{abstract}
Women suffering breast cancer who undergo chemotherapy experience side effects both physical and psychological. Complementary therapy urgently needed for relaxing patient before chemotherapy such as Autogenic and Handgrip Relaxation through self-suggestion technique. This research aim to analyze effect of autogenic and handgrip relaxation on physical aspect (chemotherapy induced nausea and vomiting), psychological aspect (anxiety) in patients with breast cancer who undergo chemotherapy at PPLK (Cancer Service Development Center) RSUD dr. Soetomo Surabaya. Method: True Experimental with post-test only with control design. 72 respondents were involved and divided into 3 treatment groups and 1 control group. Research conducted within 3 weeks after chemotherapy until next chemotherapy session on each patients. Data were analyze used MANOVA and LSD (Least Significant Difference). Results: Autogenic and handgrip relaxation influence physical aspect and psychological aspect level significantly with $\mathrm{p}=0.000$ ( $\mathrm{p}<0.05$ ). LSD test showed no difference between autogenic relaxation, handgrip relaxation, and autogenic relaxation. Conclusion: Autogenic and handgrip relaxation have an effect on nausea vomiting and anxiety patients are able to adapt and control the body's response to be adaptive.
\end{abstract}

Keywords: Breast Cancer, Autogenic, Handgrip, Chemotherapy Induced Nausea and Vomiting, Anxiety

\begin{abstract}
Abstrak: Wanita dengan kanker payudara yang menjalani kemoterapi mengalami efek samping pada aspek fisik dan aspek psikologis selama menjalani kemoterapi. Pada kondisi ini dibutuhkan terapi komplementer untuk merileksasikan pasien sebelum menjalani kemoterapi, salah satunya dengan Autogenic dan Handgrip Relaxation dengan melalui teknik sugesti diri Tujuan penelitian ini untuk mengetahui pengaruh autogenic dan handgrip relaxation terhadap aspek fisik (mual muntah) dan aspek psikologis (kecemasan) pada penderita kanker payudara yang menjalani kemoterapi di PPLK (Pusat Pengembangan Layanan Kanker) RSUD dr. Soetomo Surabaya Metode: Penelitian ini menggunakan True Experimental dengan post test only with control design. Sampel penelitian berjumlah 72 responden dan dibagi ke dalam 3 kelompok perlakuan dan 1 kelompok kontrol. Penelitian dilakukan dalam 3 minggu setelah pasien kemoterapi sampai sesi kemoterapi selanjutnya. Uji statistik yang digunakan adalah MANOVA dan LSD (Least Significant Difference) Hasil: Hasil menunjukkan bahwa ada pengaruh autogenic dan handgrip relaxation terhadap aspek fisik dan aspek psikologis dengan nilai $\mathrm{p}=0.000(\mathrm{p}<0.05)$. Dari hasil uji LSD tidak ada perbedaan intervensi antara autogenic relaxation, handgrip relaxation, dan
\end{abstract}


autogenic relaxationKesimpulan: Penerapanautogenic dan handgrip relaxation berpengaruh terhadap mual muntah dan kecemasansehingga pasien mampu beradaptasi dan mengendalikan respon tubuh menjadi adaptif pada penderita kanker payudara yang menjalani kemoterapi.

Kata Kunci : Kanker Payudara, Autogenic, Handgrip, Mual Muntah, Kecemasan,

\section{PENDAHULUAN}

Kanker payudara adalah penyakit neoplasma ganas pada jaringan payudara dan merupakan penyebab kematian paling besar bagi perempuan (Avis, 2012). Di Indonesia kanker payudara meningkat pada usia $>39$ tahun dan insiden tertinggi dijumpai pada usia 45-50 tahun sebanyak $60-80 \%$ dan lebih dari $50 \%$ kasus berada pada stadium lanjut (Yayasan Kanker Indonesia, 2015). Salah satu terapi yang diberikan pada penderita kanker payudara yaitu tindakan kemoterapi. Kemoterapi adalah proses pengobatan dengan menggunakan obat sitostatika yang bertujuan untuk memperlambat pertumbuhan sel kanker dan memperpanjang angka harapan hidup penderita (Smeltzer, et al., 2012). Wanita dengan kanker payudara yang menjalani kemoterapi mengalami efek samping secara fisik dan psikologis selama menjalani terapi (Baumann, et al,, 2013)

Aspek fisik yang dirasakan wanita dengan kanker payudara adalah mual muntah.Gralia, et al., (2012) menyebutkan bahwa lebih dari $60 \%$ pasien kanker yang dikemoterapi mengalami mual muntah/CINV (Chemotherapy Induced Nausea and Vomiting).Mual muntah didefinisikan sebagai ungkapan subjektif berupa perasaan atau sensasi yang tidak menyenangkan di bagian bagian belakang tenggorokan atau epigastrium yang disertai dengan pucat, berkeringat, saliva yang berlebihan, serta adanya kesadaran untuk muntah (Garret, et al., 2010).Kondisi mual muntah pada penderita kanker payudara tergantung dari tiap individu.yang memiliki tingkat kecemasan tinggi berpengaruh terhadap mual muntah. Faktor kecemasan, rasa takut, dan sinyal dari organ sensori (pemandangan yang menggangu, bau) mengaktifkan higher corticol centres untuk merangsang pusat muntah di medulla cortex sehingga menyebabkan reflek muntah (Mock, 2011). Kondisi mual muntah ini menyebabkan kecemasan dan stress pada pasien kanker payudara yang terkadang membuat pasien memilih untuk menghentikan siklus terapi, dan apabila siklus terapi ini dihentikan akan berpotensi mempengaruhi harapan hidup dan kualitas hidup pasien.

Pada kondisi ini dibutuhkan suatu terapi komplementer yang bertujuan untuk merileksasikan pasien sebelum menjalani kemoterapi sehingga dapat mengurangi efek samping kemoterapi pada kemoterapi selanjutnya yaitu dengan Autogenic dan Handgrip Relaxation.Autogenic dan handgrip relaxation merupakan relakasasi yang dikombinasikan oleh peneliti yang ditujukan untuk melatih pasien melakukan relaksasi tanpa tergantung pada terapisnya, yaitu melalui teknik sugesti-diri (auto suggestion technique), seseorang dapat melakukan sendiri perubahan pada kefaalan di dalam dirinya sendiri (Ackly, 2012).Autogenic relaxation dilakukan dengan membayangkan diri sendiri berada dalam keadaan damai dan tenang, berfokus pada pengaturan nafas dan detakan jantung. Menggenggam jari disertai dengan menarik nafas dalam dapat mengurangi ketegangan fisik dan emosi, karena genggaman jari akan menghangatkan titik-titik masuk dan keluarnya energi pada meridian (saluran energi) yang berhubungan dengan organ- 
organ di dalam tubuhyang terletak pada jari tangan (Lee, 2012). Titik-titik refleksi pada tangan memberikan rangsangan secara refleks (spontan) pada saat genggaman. Rangsangan tersebut akan mengalirkan semacam gelombang kejut atau listrik menuju otak kemudian diproses dengan cepat dan diteruskan menuju saraf pada organ tubuh yang mengalami gangguan, sehingga sumbatan di jalur energi menjadi lancar. Handgrip relaxation dapat mengendalikan dan mengembalikan emosi yang akan membuat tubuh menjadi rileks

Autogenic dan handgrip relaxation menghasilkan rasa nyaman dan rileks pada penderita kanker payudara sehingga menghasilkan stimulus dari serabut sensori asenden dan mengaktifkan Reticular Activating System (RAS) di korteks cerebral, sehingga mempengaruhi sistem limbik dan sistem saraf otonom untuk menstimulasi pengeluaran endorphine yang mengakibatkan respon relaksasi (Callaghan, 2012). Model adaptasi Roy membantu perawat meningkatkan penyesuaian diri klien terhadap berbagai tantangan terkait sehat dan sakit serta meningkatkan adaptasi individu dan kelompok pada 4 mode adaptif sehingga kesehatan, kualitas hidup yang optimal, serta kematian yang bermartabat bisa tercapai (Alligood \& Tomey, 2006). Outcome yang diharapkan pada evaluasi akhir yaitu adanya perilaku yang adaptif dalam menghadapi kemoterapi dan efek sampingnya sehingga aspek fisik (mual muntah), aspek psikologis (kecemasan) berkurang sehingga kualitas hidup akan meningkat

\section{METODE}

Penelitian ini menggunakan True Experimentaldengan desain penelitian post test only with control design.Teknik sampling pada penelitian ini adalah consecutive sampling.Populasi terjangkau dalam penelitian ini adalah pasien kanker payudara yang menjalani kemoterapi di PPLK (Pusat Pengembangan Layanan Kanker) Poli Onkologi RSUD dr Soetomo Surabaya.Sampel penelitian yang memenuhi kriteria inklusi berjumlah 72 responden yang dibagi dalam 4 kelompok, yaitu 18 responden kelompok autogenic relaxation, 18 responden kelompok handgrip relaxation, 18 kelompok autogenic dan handgrip relaxation, dan 18 kelompok kontrol. Pelaksanaan dilakukan dalam 3 minggu setelah pasien kemoterapi sampai sesi kemoterapi selanjutnya.dengan durasi waktu 10-15 menit setiap pagi hari selama 6x/minggu. Variabel independen dalam penelitian ini adalah autogenic dan handgrip relaxation dan variabel dependennya adalah aspek fisik (mual muntah), aspek psikologis (kecemasan).Uji statistik yang digunakan adalah MANOVA untukmenguji hipotesisnya dan LSD (Least Significant Difference) untuk mengetahui adanya perbedaan pada masing-masing kelompok.

\section{HASIL \& PEMBAHASAN \\ Hasil}

\section{a. Nilai Aspek fisik ; mual muntah (post test only)}

Data karakteristik variabel responden ini menguraikan aspek fisik; mual muntah yang diukur sesudah diberikan intervensi

Tabel 1. Distribusi nilai variabel mual muntah pada kelompok perlakuan dan kontrol di RSUD dr Soetomo Surabaya tahun $2017(n=72)$

\begin{tabular}{|c|c|}
\hline Kelompok & $\mathrm{N} \quad$ Mean $\pm \mathrm{SD}$ \\
\hline K1 (Autogenic relaxation) & $18 \quad 7.17^{\mathrm{a}} \pm 3.485$ \\
\hline K2 (Handgrip Relaxation & $18 \quad 8.56^{\mathrm{a}} \pm 3.166$ \\
\hline $\begin{array}{lll}\text { K3 (Autogenic dan } \\
\text { Handgrip Relaxation) }\end{array}$ & $18 \quad 7.11^{\mathrm{a}} \pm 2.477$ \\
\hline K4 (Kontrol) & $18 \quad 10.56^{\mathrm{b}} \pm 2.595$ \\
\hline \multicolumn{2}{|l|}{ ANOVA $p=0.002$} \\
\hline $\begin{array}{l}\text { Berdasarkan pada } \mathrm{t} \\
\text { menunjukkan bahwa res } \\
\text { menurun pada kelomp } \\
\text { handgrip relaxation (K}\end{array}$ & $\begin{array}{l}\text { abel } 11 \text { diatas } \\
\text { ata mual muntah } \\
\text { o autogenic dan } \\
\text { 3)sebesar } 7.11 \pm\end{array}$ \\
\hline
\end{tabular}


3.485, sedangkan rerata peningkatan mual muntah terdapat pada kelompok kontrol (K4) sebesar $10.56 \pm 2.595$. Hasil uji Manova didapatkan $p=0.002$ sehingga minimal ada sepasang kelompok yang memiliki perbedaan rerata jumlah mual muntah. Untuk mengetahui pasangan kelompok mana yang berbeda maka dilanjutkan dengan uji Post Hoc dengan menggunakan LSD (Least Significance Difference).

Dari hasil uji LSD dapat diketahui bahwa nilai mual muntah pada K1 tidak mempunyai perbedaan yang bermakna dengan K2 $(p=0.163), \mathrm{K} 3(p=0.955)$ dan mempunyai perbedaan yang bermakna dengan $\quad \mathrm{K} 4 \quad(p=0,001), \quad$ sedangkan $\quad \mathrm{K} 2$ mempunyai perbedaan yang bermakna dengan K4 $(p=0.046)$, dan tidak mempunyai perbedaan dengan $\mathrm{K} 3 \quad(\mathrm{p}=0.147) . \quad \mathrm{K} 3$ mempunyai perbedaan yang bermakna dengan K4 $(p=0.001)$

\section{b. Nilai Aspek psikologis ; kecemasan (post tes only)}

Data karakteristik variabel responden ini menguraikan aspek psikologis; kecemasan yang diukur sesudah diberikan intervensi Tabel 2. Distribusi nilai variabel kecemasan pada kelompok perlakuan dan kontrol di RSUD dr Soetomo Surabaya tahun 2017 $(\mathrm{n}=72)$

Kelompok $\quad$ N Mean \pm SD

K1 (Autogenic relaxation) $18 \quad 50.94^{\mathrm{a}} \pm 10.941$ K2 (Handgrip Relaxation $18 \quad 55.56^{\mathrm{ab}} \pm 10.848$

K3 (Autogenic dan $18 \quad 45.28^{\mathrm{a}} \pm 10.063$ Handgrip Relaxation)

\begin{tabular}{ccc}
\hline K4 (Kontrol) & $18 \quad 59.72^{\mathrm{b}} \pm 8.288$ \\
\hline ANOVA $<0.0001$ & & \\
\hline
\end{tabular}

Berdasarkan pada tabel 4 diatas menunjukkan bahwa rerata penurunan kecemasan pada kelompok autogenic dan handgrip relaxation (K3)sebesar $45.28 \pm$ 10.063 sedangkan rerata peningkatan kecemasan terdapat pada kelompok kontrol (K4) sebesar $59.72 \pm 8.288$
Hasil uji Manova didapatkan $p<0,0001$ sehingga minimal ada sepasang kelompok yang memiliki perbedaan rerata kecemasan Untuk mengetahui pasangan kelompok mana yang berbeda maka dilanjutkan dengan uji Post Hoc dengan menggunakan LSD (Least Significance Difference).

Dari hasil uji LSD dapat diketahui bahwa nilai kecemasan pada $\mathrm{K} 1$ tidak mempunyai perbedaan yang bermakna dengan K2 $(p=$ $0.175)$, K3 $(p=0.097)$ dan mempunyai perbedaan yang bermakna dengan K4 $(p=0,011)$, sedangkan $\mathrm{K} 2$ mempunyai perbedaan yang bermakna dengan K3 $(p=0.003)$, dan tidak mempunyai perbedaan dengan K4 $(\mathrm{p}=0.220)$. K3 mempunyai perbedaan yang bermakna dengan K4 $(p<0.0001)$.

\section{Uji perbedaan antar kelompok}

a. Pengaruh Autogenic Relaxation terhadap aspek fisik; mual muntah dan apek psikologis; kecemasan pada kelompok kontrol dan perlakuan

Tabel 3. Hasil uji beda rerata (autogenic relaxation) pada kelompok perlakuan dan kelompok kontrol di RSUD dr Soetomo Surabaya tahun 2017

\begin{tabular}{lll}
\hline Kelompok & $\mathrm{p}$ value & Keterangan \\
\hline Mual muntah & 0.001 & Signifikan \\
\hline Kecemasan & 0.011 & Signifikan
\end{tabular}

Berdasarkan hasil uji LSD sesudah intervensi pada kelompok perlakuan dan kontrol, untuk variabel aspek fisik; mual muntah dan aspek psikologis; kecemasan, dan kadar kortisol didaptkan nilai $\mathrm{p}$ value yang signifikan. Pada variabel mual muntah $\mathrm{p}=0.001$, kelelahan $\mathrm{p}=0.000$, kecemasan $\mathrm{p}=0.011$, kadar kortisol $\mathrm{p}=0.005$ menunjukkan ada perbedaan yang signifikan terhadap aspek fisik; mual muntah dan aspek psikologis; kecemasan, antara kelompok perlakuan dan kontrol setelah mendapatkan intervensi autogenic relaxation 


\section{b.PengaruhHandgrip Relaxation terhadap aspek fisik; mual muntah dan apek psikologis; kecemasan,pada kelompok kontrol dan perlakuan}

Tabel 4. Hasil uji beda rerata (handgrip relaxation) pada kelompok perlakuan dan kelompok kontrol di RSUD dr Soetomo Surabaya tahun 2017

\begin{tabular}{lll}
\hline Kelompok & $\mathrm{p}$ value & Keterangan \\
\hline Mual muntah & 0.046 & Signifikan \\
\hline Kecemasan & 0.220 & Tidak Signifikan \\
\hline Berdasarkan & hasil uji & LSD sesudah
\end{tabular}
intervensi pada kelompok perlakuan dan kontrol, untuk variabel aspek fisik; mual muntah didaptkan nilai $p$ value yang signifikan. Pada variabel mual muntah $\mathrm{p}=0.046$, menunjukkan ada perbedaan yang signifikan terhadap aspek fisik; mual muntah antara kelompok perlakuan dan kontrol setelah mendapatkan intervensi autogenic relaxation, sedangkan pada variabel kecemasan menunjukkan hasil tidak signifikan yaitu $\mathrm{p}=0.220$.

\section{c.Pengaruh Autogenic dan Handgrip} Relaxation terhadap aspek fisik; mual muntah dan apek psikologis; kecemasan pada kelompok kontrol dan perlakuan

Tabel 5. Hasil uji beda rerata (autogenic dan handgrip relaxation) pada kelompok perlakuan dan kelompok kontrol di RSUD dr Soetomo Surabaya tahun 2017

\begin{tabular}{lll}
\hline Kelompok & $\mathrm{p}$ value & Keterangan \\
\hline Mual muntah & 0.001 & Signifikan \\
\hline Kecemasan & 0.000 & Signifikan \\
\hline Berdasarkan & hasil uji & LSD sesudah
\end{tabular}
intervensi pada kelompok perlakuan dan kontrol, untuk variabel aspek fisik; mual muntah dan aspek psikologis; kecemasan didapatkan nilai $\mathrm{p}$ value yang signifikan. Pada variabel mual muntah $\mathrm{p}=0.001$, kecemasan, $\mathrm{p}=0.000$ yang menunjukkan ada perbedaan yang signifikan terhadap aspek fisik; mual muntah dan aspek psikologis ; kecemasan antara kelompok perlakuan dan kontrol setelah mendapatkan intervensi kombinasi autogenic dan relaxation.

\section{PEMBAHASAN}

Pada variabel aspek fisik; mual muntah terdapat perbedaan antara kelompok perlakuan dan kelompok kontrol dengan signifikasi $\mathrm{p}=0.001$. Pelaksanaan autogenic dan handgrip relaxation yang teratur yaitu setiap pagi selama 6 hari dalam 21 hari dengan durasi waktu 10-15 menit dapat menurunkan mual muntah dibandingkan dengan kelompok kontrol yang tidak diberikan relaksasi. Kombinasi relaksasi seperti autogenic dan handgrip relaxation yang dilakukan oleh pasien kanker payudara akan menyebabkan rasa rileks dan nyaman sehingga mengaktifkan $\mathrm{CRH}$ dan merangsang pituitary untuk meningkatkan sekresi $\beta$ endorfin yang dapat menimbulkan perasaan senang dan menghilangkan kegelisahan. Hal ini berpengaruh positif terhadap respon relaksasi. Sekresi endorphin ini akan menjadi antiemetik alami dengan cara menghambat impuls mual di CTZ dan vomiting center di sistem saraf pusat dan medulla oblongata sehingga mual muntah dapat berkurang (Tipton, et all., 2007). Dalam intervensi pada penelitian ini, terbukti bahwa efek positif dari autogenic relaxation berhasil meningkatkan keefektifan mengurangi mual muntah kemoterapi.Pada penerapan autogenic dan handgrip relaxation, pelaksanaan 5 poin autogenic relaxation terutama untuk poin ke 4 yaitu sensasi hangat pada abdomen harus benar-benar diaplikasikan karena bertujuan untuk meregulasi fungsi dari organ abdomen dan rileksasi dari kondisi emosi dan perasaan mual muntah. Pada 16 responden yang tidak mengalami mual muntah setelah kemoterapi, pasien memang benar-benar mengaplikasikan autogenic dan handgrip relaxation dengan rutin setiap pagi di lingkungan rumah yang tenang dan support sistem keluarga yang baik. Peran support sistem dan dukungan keluarga sangat 
dibutuhkan untuk tercapainya perasaan yang rileks. Pemberian motivasi pada responden diterapkan secara berkala agar niat dan kemauan responden untuk melakukan autogenic dan handgrip relaxation muncul dari dalam diri sendiri.

Pada variabel aspek psikologis; kecemasan terdapat perbedaan antara kelompok perlakuan dan kelompok kontrol dengan signifikasi p <0.0001.Menurut Bowden (2012) relaksasi yang dikombinasikan seperti autogenic dan handgrip relaxation merupakan relaksasi yang memiliki kekuatan paling tinggi terhadap penurunan kecemasan.Hasil penelitian Bowden (2012) lebih lanjut, klien menyatakan merasakan sensasi hangat setelah autogenic relaxation.Hal ini sesuai dengan hasil penelitian ini bahwa relaksasi ini memberikan sensasi hangat dan berat yang berpengaruh terhadap penurunan kecemasan dan hormon penyebab stress, yaitu kortisol.Saundres menyatakan bahwa rasa hangat tersebut merupakan hasil vasodilatasi arteri perifer sedangkan sensasi berat merupakan hasil dari hilangnya tekanan otot tubuh.Penurunan kecemasan ekstrim terjadi pada 3 orang. Berdasarkan data demografi, responden menderita kanker payudara sejak 1-1,5 tahun yang lalu dan sekarang masih menjalani pengobatan kemoterapi. Dukungan keluarga dan usaha melakukan koping yang adaptif mempengaruhi proses dalam beradaptasi dengan penyakit dan persepsi negatif yang ada dalam pemikiran mereka (Mock, 2011). Pasien dapat mengatasi kecemasannya dengan menggunakan sumber koping di lingkungan sekitarnya.Sumber koping tersebut adalah asset ekonomi, kemampuan menyelesaikan masalah, dukungan soisal keluarga dan keyakinan budaya dapat membantu individu dalam menggunakan mekanisme koping yang adaptif (Utami, 2013).Dukungan keluarga diperlukan pasien dalam membantu menurunkan kecemasan, meningkatkan semangat hidup dan komitmen pasien untuk tetap menjalani pengobatan kemoterapi. Selain faktor eksternal, dalam menurunkan kecemasan diperlukan juga faktor internal, salah satunya dengan teknik relaksasi. Relaksasi dapat memutuskan pikiran-pikiran negatif yang menyertai kecemasan

Model adaptasi Roy membantu perawat meningkatkan penyesuaian diri klien terhadap berbagai tantangan terkait sehat dan sakit serta meningkatkan adaptasi individu dan kelompok pada 4 mode adaptif sehingga kesehatan, kualitas hidup yang optimal, serta kematian yang bermartabat bisa tercapai (Alligood\& Tomey, 2006). Kanker payudara berhubungan erat dengan tingkat stress yang tinggi sehingga mempengaruhi proses pertumbuhan dan perkembangan. Perawat diharapkan mampu merencanakan dan menentukan intervensi yang efektif untuk meningkatkan perilaku adaptif sehingga kualitas hidup yang optimal akan tercapai (Roy \& Andrews, 2010). Pada penelitian ini didapatkan data bahwa stimulus fokal bagi tiap perubahan tersebut salah satunya adalah kemoterapi.Pada pasien kanker payudara, tingkat keparahan penyakit dan kemoterapi memiliki keterkaitan erat dengan respon biopsikosoial dan harus dipertimbangkan sebagai stimulus fokal lingkungan. Stimulus konstektual yang perlu dipertimbangkan antara lain usia, pendidikan, pekerjaan, status pernikahan, sesi kemoterapi, dan stadium. Perubahan akibat kemoterapi memicu proses koping baik melalui subsistem regulator maupun subsistem kognator. Berbagai masalah keperawatan bisa muncul terkait efek samping kemoterapi antara lain kurang pengetahuan tentang kemoterapi, aspek fisik yang timbul yaitu mual muntah dan kelelahan, aspek psikologis yaitu kecemasan.

Pemberian autogenic dan handgrip relaxation mempengaruhi sistem limbik untuk mensinkronisasi gelombang otak 
menuju gelombang $\alpha$ yang menimbulkan perasaan tenang (Hurgobin, 2006).Keadaan ini akan direspon oleh hipotalamus dengan menurunkan aktivitas saraf simpatis yang mempengaruhi medula adrenal untuk menurunkan sekresi hormon katekolamin, meningkatkan vasodilatasi pembuluh darah, meningkatkan vaskularisasi yang pada akhirnya menurunkan kecemasan dan membuat suasana hati positif pada pasien kanker payudara. Selain itu hipotalamus menurunkan sekresi corticotropin releasing factor (CRF) yang akan merangsang pitutary menurunkan sekresi adrenocorticotropin hormone (ACTH). Kemudian ACTH melalui korteks adrenal menurunkan sekresi kortisol, dan CRF juga merangsang pituitary untuk meningkatkan sekresi $\beta$ endorfin yang dapat menimbulkan perasaan senang dan menghilangkan kegelisahan (Stetter, 2012).Teknik relaksasi ini memfasilitasi kapasitas pikiran sehingga berpengaruh pada gejala fisik dan fungsi tubuh sehingga menciptakan harmonisasi antara pikiran dan tubuh. Keselarasan ini akan meningkatkan kesehatan dan memfasilitasi kesembuhan fisik dan psikologis yang pada akhirnya akan meningkatkan kualitas hidup terkait kesehatan klien.

\section{SIMPULAN}

Autogenic dan Hangrip relaxation dapat mengurangi berbagai dampak negatif dari kemoterapi, yaitu aspek fisik (mual muntah) dan aspek psikologis (kecemasan) sehingga outcome yang diharapkan yaitu adanya perilaku pasien yang adaptif dalam menghadapi kemoterapi dan mengurangi efek samping berbagai dampak negatif dari kemoterapi, sehingga pasienakan mempunyai koping adaptif dalam menjalani kemoterapi

\section{DAFTAR PUSTAKA}

Ackly, NP, 2012, Terapi Modalitas Keperawatan, Balai Penerbit FKUI, Jakarta

Alligood, M. R. \& Tomey, A. M, 2006, Nursing Theorists and Their Work, 6th.ed, Mosby Missouri

Avis NE, Crawford S \& Manuel J, 2012, 'Quality of Life among younger women with breast cancer', Journal of Clinical Oncology, vol. 23, hal 3322-3330

Baumann FT, Bloch W, Weissen A, BrochausM, Beulertz J, Zimmer P, Sreckmann F, 2013. 'Physical activity in breast cancer patients during medical treatment and in the aftercare- a review', Journal of Clinical Oncology , 8 (5), 330-334

Bowden, A., Lorenc, A., dan Robinson, N, 2012, 'Autogenic training as a behavioural approach to stress: A prospective cohort study', Primary Health Care Research \& Development 13: $175-185$

Callaghan, 2012, 'Objective and Constructivist Music Therapy Research in Oncology and Palliative Care: An Overview and Reflection', Music and Medicine Journal, vol.1, no.4, hal.41-55

Garret, K., Tsuruta, K., Walker, S., Jackson, S., \& Sweat, M., 2013.'Managing Nausea and Vomiting', Journal of Critical Care Nurse, vol.1, no.3, hal.1535.

Gralia, JR, Houlihan, NG, \& Messner C, 2012, 'Understanding and Managing Chemotherapy Side Effects', Oncology Nursing Forum

Hurgobin, S, 2006, 'Autogenic Training for reducing anxiety and promoting psychological well-being', KwaZuluNatal : Faculty of Arts University of Zululand

Lee, J., Dodd, M., Dibble, S., \& Abrams, D, 2011, 'Review of Handgrip Relaxation for Chemotherapy-induced nausea and 
vomiting control', Journal of Pain and Symptom Management

Mock, V, 2011. 'Physical functioning during breast cancer treatment', Oncology Nursing Society.Volume.42, hal. 14091416

Oberg, E, 2009, 'Mind Body Techniques to Reduce Hypertension's Chronic Effects', Integrated Medicine Journal, vol 1, no 1, hal 1-7

Roy, Sr. Cand Andrews, 2010, The Roy Adaptation Model : The Definitive Statement, Norwalk: Appleton \& Lange Smeltzer, S.C., Bare, B.G., Hinkle , J.L., \& Cheevar, K.H., 2012, 'Textbook of Medical Surgical Nursing', Brunner \& Suddarth's, ed 11, Lippincott Williams \& Wilkins, a Wolter Kluwer Bussiness, Philadhelpia.

Stetter, Friedhelm, 2012, Autogenic Training : a meta analysis of clinical outcome studies, Germany : Plenum Publishing Corporation

Tavio, M, Milan, 2011, 'Cancer-related fatigue', International Journal of Oncology 21(5) : 1093-1099

Tipton, J. M., Roxanne, M., Laurel, B., et all, 2007, 'Putting evidence into practice : evidence-based interventions to prevent, manage, and treat chemotherapy-induced nausea and vomiting, Journal of Oncology Nursing, (11) 69-78.

Utami, 2013. 'Hubungan Dukungan Keluarga Terhadap Tingkat Kecemasan Kemoterapi Pada Pasien Kanker Serviks di RSUD Dr. Moewardi, Vol. 10, No. 1, Yayasan Kanker Indonesia, 2015, Pusat data dan informasi kanker payudara, Jakarta 